\title{
Von Lenin zu Timur
}

Erhard Taverna

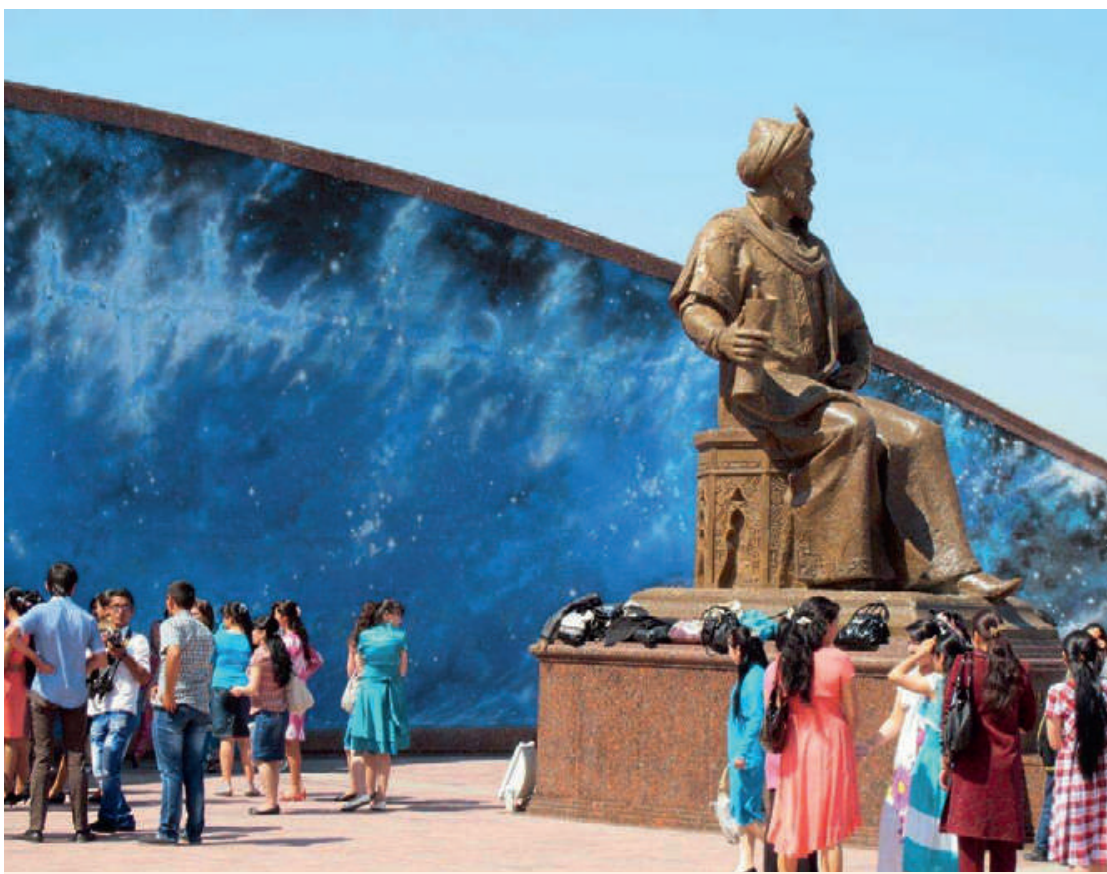

Ulug'beg, König und Astronom.
Die Luft ist klar und wolkenlos blau. Kastanien blühen, und Robinien duften in den Strassen von Samarkand. Alexander der Grosse und Marco Polo bewunderten die Stadt, Dschingis Khan legte sie in Schutt und Asche. Die Herrschaft der Timuriden führte sie zu neuer Pracht, und postsowjetisches Blattgold verhalf zum frischen Glanz. Heute, am ersten Mai, ist schulfrei. Seit der Unabhängigkeit von 1991 gibt es keine Paraden mehr. In der Gräberstadt, mitten im riesigen Friedhof auf den Lehmhügeln des antiken Afrasiab, drängen sich Schulklassen, Wallfahrer, Besucher vom Lande und Touristen aller Nationen. Erde zu Erde. Was aussieht wie Wälle und Klippen, waren einmal befestigte Mauern. Die enge Strasse säumen beidseits Mausoleen. Glasierte, vielfarbige Kacheln bedecken die Aussenwände, im Innern zieht sich bemalter Stuck bis unter die Decke. Auf den Fayenceplatten spielt das Licht. Arabesken, geometrische Ornamente und Kalligraphien verbin- den verschlungene Botschaften vom Paradies der Gläubigen. Lachende Mädchen in Schuluniformen mit weissen Schürzen und Haarmaschen gehen durch die Portale. Frauen in Hosen, unter bunten Umhängen mit golden-silbrig glitzernden Stickereien, alte Männer mit schwarz-weissen Kappen, weissbehemdete Burschen mit Krawatten und fotografierende Jeansträger suchen ihren Weg durch die Gassen der Nekropole. Ein sinnlich-festliches, farbenfrohes, friedliches Getümmel. Dem, der beim Hinauf- und Hinabgehen gleich viele Stufen zählt, werden die Sünden vergeben. Wer sich von einem Heiligen etwas wünscht, steckt einen Geldschein zwischen eine Astgabel oder wickelt ein Stoffbändchen um einen Zweig.

\section{Samarkand: Alexander der Grosse und Marco Polo bewunderten die Stadt, Dschingis Khan legte sie in Schutt und Asche.}

Das Wünschen hat nicht immer geholfen. «Es war einmal und es war nicht», so beginnen viele usbekische Märchen. Zentralasien war immer ein Durchgangsland am Rande mächtiger Imperien, ein Schmelztiegel für Nomadeninvasoren und sesshafte Einheimische, der Körperbau, Hautfarbe und Gesichtszüge vielfältig geprägt hat. Die Zaren brachten russische Bauern ins Land, mit ihnen Tisch, Stuhl und Ofen, dazu die Eichen- und Kastanienbäume. Stalin deportierte Wolgadeutsche und Koreaner nach Usbekistan. Er alphabetisierte das Land und liquidierte die Elite. Die Nachfolger bauten auf den Erdbebentrümmern von Taschkent eine neue Stadt und opferten der Baumwolle den Aralsee. Eine Altlast unter anderen.

Wo Leninstatuen standen, steht, sitzt oder reitet Timur, mit Beinamen Lenk, der hinkende, im Westen als Tamerlan bekannt. Das einseitig verkürzte Gebein hat 1941 ein forensisches Team bestätigt. Eine Legende führt den zeitgleichen Angriff der Wehrmacht auf diese Grabschändung zurück. Vor der Wende war Timur in allen Schulbüchern ein gnadenloser Wüterich, heute mutiert er zum nationalen Superman. Vermutlich trifft beides zu. Denn für einmal wurde aus dem Grenzland eine Weltmacht, deren Herrschaftsgebiet vom Ganges bis an das Mittelmeer reichte. Kaum ein Reich oder eine Dynastie der wechselvollen, blutigen Geschichte Zentralasiens hat länger als zwei oder drei Generatio- 


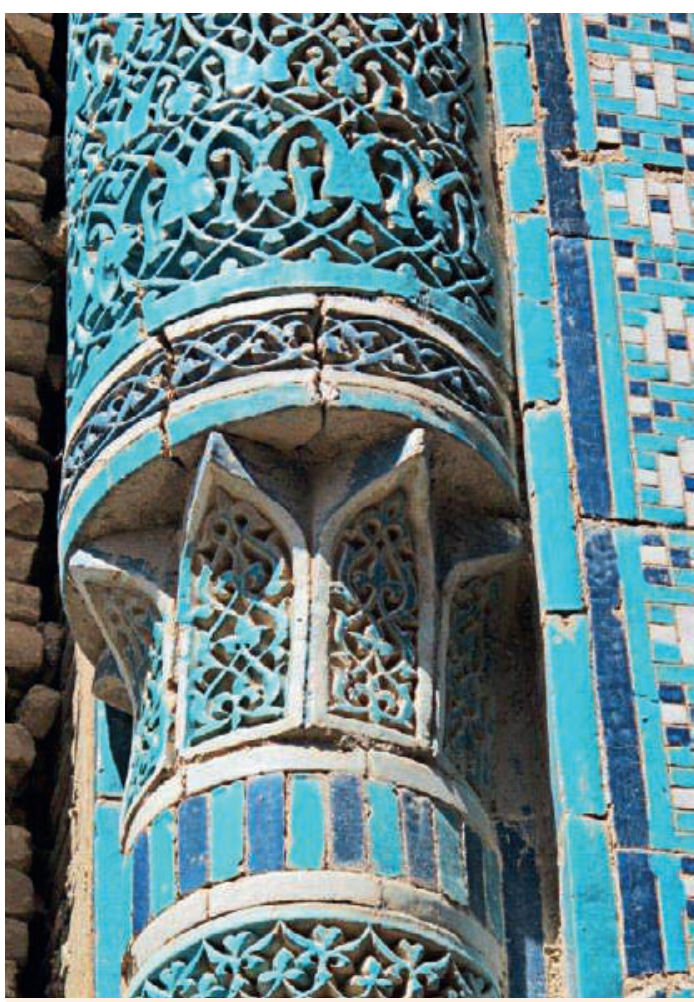

Detail aus der Gräberstadt Shohizinda.

nen gedauert. Niemand wusste das besser als Timurs Enkel Ulug'beg, der als Vizekönig von 1409 bis 1449 Samarkand regierte. Mit seinem Ausspruch: «Die Religionen vergehen wie Nebel, Reiche zerstören sich selbst, aber die Arbeiten der Gelehrten bleiben für alle Zeiten» sollte er recht behalten. Ein Mondkrater trägt heute seinen Namen. Er liess ein dreistöckiges Observatorium bauen und leitete eine Schule für Astronomen. Davon geblieben ist das kleine Stück eines riesigen Goniometers, das 1908 ein russischer Archäologe entdeckte. Von der kreisrunden Plattform neben dem kleinen Museum geht der Blick über die ausgedehnten, baumreichen Stadtviertel hinaus in die fruchtbare, von Bergen begrenzte Ebene. Ulug'begs Sternenkatalog war der erste, der seit Ptolemäus auf neuen Messungen beruhte. Seine Positionsangaben dienen bis heute als Referenzwerte für GPS-Systeme. Die Gelehrten berechneten sekundengenau das siderische Jahr und den Winkel der Erdachse zur Ekliptik. Nach seiner Ermordung zerstörten Fanatiker Gebäude und Bibliothek. Ein Schüler entkam mit den Sternentafeln nach Täbris. Er lehrte in Istanbul, von wo aus die Tabellen nach Westeuropa gelangten. Die Timuriden bauten Schulen, Moscheen und Paläste, die mit ihren baulichen und künstlerischen Neuerungen zu Vorbildern für die ganze islamische Welt wurden. Den Registan, einen ehemaligen Marktplatz, begrenzen drei grosse Medresen, wovon Ulug'begs Hochschule als eine der ältesten und schönsten gilt. Timurs Palast Gur-e Amir mit seiner gefalteten Melonenkuppel und sein Grabmonument für die legendäre Bibi Hanim glänzen in der Abendsonne wie Traumbilder aus 1001 Nacht.

Im jungen Staat sind Kinder und Jugendliche die Mehrheit. Wenn ältere Menschen die wohltuend reklamefreie U-Bahn in der Hauptstadt besteigen, bekommen sie unaufgefordert einen Sitzplatz. Neun Jahre Grundschule sind obligatorisch und im Prinzip kostenlos. Wer weiter studiert, zum Beispiel Medizin, besucht für 1-2 Jahre ein College und lernt danach während sieben Jahren an einer Universität ein Spezialgebiet. Doziert wird usbekisch und/oder russisch. Seit der Unabhängigkeit wird die Landessprache kyrillisch und lateinisch geschrieben. Die Schrift trennt heute Jung und Alt. Vielleicht mit ein Grund, dass es keine Buchhandlungen gibt, die diesen Namen wirklich verdienen. Wichtigster Wirtschaftspartner bleibt Russland. Südkoreaner montieren Autos und bauen mit den Deutschen Strassen. Ein gerades Stück Autobahn vor Taschkent ist mit Betonplatten verstärkt. 1979 landeten hier sowjetische Militärmaschinen mit Nachschub für Afghanistan. Im Süden benützt die Bundeswehr bei Termez den Flussübergang über den Amu-darya. Wir passieren bei Nieselregen die zahlreichen Strassenkontrollen. Im südlichsten Transoxanien haben Archäologen in den 1930er Jahren buddhistische Heiligtümer freigelegt. Stupen, Buddhas und Wandgemälde. Ein Komplex von Höhlen und Klostermauern liegt in der Militärzone. Besichtigen verboten. The great Game, der imperiale Machtpoker, einst zwischen dem Zarenreich im Norden und dem britischen Empire im Süden, geht in eine neue Runde. Die Amerikaner bekamen Überflugsrechte für Wirtschaftshilfe, bald ziehen sie ab, wie alle Vorgänger. Es droht Streit um die Nutzung der Wasserzuflüsse vom Altai- und Pamirgebirge. Es gibt nationalistische und religiöse Fanatiker, und nicht alle Nachbarstaaten sind stabil. Über die heutige Seidenstrasse wird Opium geschmuggelt und Öl geleitet.

Auf Timurs Schlachtross gurren die Tauben. Usbekistan besitzt neben Baumwolle und einer ergiebigen Landwirtschaft auch Erdgas, Gold, Uran und seltene Erden. Doch die wahren Schätze sind seine Menschen. 